\title{
Population-based study of central post-stroke pain in Rimini district, Italy
}

This article was published in the following Dove Press journal:

Journal of Pain Research

16 September 2013

Number of times this article has been viewed

\section{William Raffaeli' \\ Cristina E Minella ${ }^{2}$ \\ Francesco Magnani ${ }^{3}$ \\ Donatella Sarti ${ }^{3}$}

'ISAL Foundation, Institute for Research on Pain, Torre Pedrera, Rimini, Italy ${ }^{2}$ Pain Therapy Unit, Fondazione IRCCS Policlinico San Matteo, Pavia, Italy ${ }^{3}$ Department of Pain Therapy and Palliative Care, Infermi Hospital, Rimini, Italy
Correspondence: Cristina E Minella Pain Therapy Unit, Fondazione IRCCS Policlinico San Matteo, 27 I 00 Pavia, Italy Tel +390382502627

Email c.minella@smatteo.pv.it
Abstract: Central post-stroke pain (CPSP) is still an underestimated complication of stroke, resulting in impaired quality of life and, in addition to the functional and cognitive consequences of stroke, the presence of CPSP may be associated with mood disorders, such as depression, anxiety, and sleep disturbances. This type of pain may also impair activities of daily living and further worsen quality of life, negatively influencing the rehabilitation process. The prevalence of CSPS in the literature is highly variable (1\%-12\%) according to different studies, and this variability could be influenced by selection criteria and the different ethnic populations being investigated. With this scenario in mind, we performed a population-based study to assess the prevalence of CPSP and its main features in a homogeneous health district (Rimini, Italy), including five hospitals for a total population of 329,970 inhabitants. From 2008 to 2010, we selected 1,494 post-stroke patients and were able to interview 660 patients, 66 (11\%) of whom reported pain with related tactile and thermal hyperesthesia, accompanied by needle puncture, tingling, swelling, and pressure sensations. Patients reported motor impairment and disability, which influenced their working ability, rehabilitation, and social life. Despite this severe pain state, there was a high percentage of patients who did not receive adequate treatment for pain.

Keywords: stroke, central post-stroke pain, disability

\section{Introduction}

Stroke is a leading cause of morbidity and mortality. ${ }^{1}$ In Europe, the annual standardized incidence of stroke is 113 per $100,000 .{ }^{2}$ Currently, the clinical burden of stroke and transient ischemic attack exceeds that of coronary heart disease. ${ }^{3}$ Recently, Sacco et al found that the annual incidence rates standardized to the Italian population ranged from 175 to 360 per 100,000 in men and from 130 to 273 per 100,000 in women, with $67 \%-82.6 \%$ being ischemic strokes. ${ }^{4}$

Patients with stroke may suffer several types of pain, including articular pain, musculoskeletal pain, painful spasticity, headache, and neuropathic central post-stroke pain (CPSP). Central post-stroke pain is one of a group of chronic pain conditions that are termed central neuropathic pain, because pain is due to a lesion or a disease affecting the central somatosensory system. Central neuropathic pain may be caused by different pathologic conditions affecting the central somatosensory system, including ischemic and hemorrhagic vascular lesions (eg, CPSP), tumors, trauma, surgical injury, and thalamic arteriovenous malformations. ${ }^{5}$ In the past, CPSP was attributed to a thalamic lesion and known as Dejerine and Roussy syndrome, but is now also associated with extrathalamic lesions because the symptoms and severity of CPSP in thalamic versus extrathalamic stroke do not differ. ${ }^{6}$ 
According to the new definition of neuropathic pain, ${ }^{7}$ CPSP is defined as "pain arising as a direct consequence of a cerebrovascular lesion of the somatosensory system in the central nervous system". ${ }^{8}$ The diagnosis of CPSP is challenging, and is often one of exclusion because there are no pathognomonic features or uniform signs, except neurologic damage, and the characteristics and descriptions of CPSP vary substantially between patients. ${ }^{8}$ It has been suggested that the diagnosis should be based on a combination of clinical history and radiologic evaluation in order to recognize the lesion (type, location, and size) and to exclude other possible central causes of pain. ${ }^{6}$

Damage to the central nervous system (CNS) may result in motor and/or sensory deficits, (as ipo/anesthesia), accompanied by positive neurologic symptoms (thermal and/or mechanical allodinia/hyperalgesia, paresthesias) and intractable pain, which may be characterized by spontaneous and/ or evoked pain with or without associated dysesthesia and/or paresthesia. ${ }^{9}$ Data in the literature suggest that age, gender, and side of the lesion in the CNS could not be considered predictors of CPSP. ${ }^{6,10,11}$

Although the literature indicates that chronic pain after a stroke is a common condition, its incidence is highly variable $(8 \%-46 \%),{ }^{12-14}$ while the prevalence of CPSP has been estimated to be $1 \%-12 \% .^{10,12,14-17}$

Most of the literature also classifies skeleton muscular syndromes as post-stroke pain. The prevalence of pain is reported to be as high as $35 \%-60 \%$ in these syndromes, which are secondary to motor dysfunction and/or ankylosis, and pain is mainly of the nociceptive type.

Hansen et al recently investigated the incidence of all common pain types following stroke in a prospective study using 3-month and 6-month follow-up interviews. ${ }^{18}$ At the 6-month follow-up, newly developed pain was reported by $45.8 \%$ of the patients (headache by $13.1 \%$, shoulder pain by $16.4 \%$, other joint pain by $11.7 \%$, other pain by $20.0 \%$, and pain evoked by light touch or thermal stimuli by $8.0 \%$ ). Further, $10.5 \%$ of the patients were classified as having possible CPSP and $33.6 \%$ of the patients with newly developed pain reported a moderate to severe impact on daily life.

The great complexity of clinical features generates difficulty in clinical evaluation. ${ }^{19}$ Moreover, there are no biomarkers that can discriminate between central and peripheral disnociceptive factors. A critical element, which may be a source of bias in the literature, is the timing of clinical evaluations, that influence the outcome of the investigation, since CPSP does not have an established onset time and possible intervals may have such wide ranges (from days up to 10 years) that the investigations must absolutely take into account the timing of the study.

Klit et al published a population-based study on pain following stroke and included a control group. ${ }^{13}$ The authors reported that development of new onset chronic pain was reported by $39.0 \%$ of stroke patients and $28.9 \%$ of reference subjects. Jönsson et al reported the prevalence, intensity, and temporal evolution of pain in an unselected group of stroke survivors; they estimated that after 16 months, about $21 \%$ of patients suffered from moderate to severe pain. ${ }^{14}$ The burden of this pathologic condition includes not only pain symptoms and positive/ negative neurologic sensations, but also their severe impact on quality of life for patients.

In stroke survivors, several factors other than pain may influence quality of life, such as motor impairment, loss of work, depression, ${ }^{20,21}$ loss of sleep and appetite, poor social interaction, and disability, ${ }^{22}$ which may impair activities of daily living and worsen quality of life, negatively influencing the rehabilitation process. ${ }^{23}$

The primary objective of our population-based study was to identify, by telephone interview, the prevalence of CPSP in patients who had had a stroke and were hospitalized for the acute event in district hospitals in Rimini between 2008 and 2010. The secondary objective was to evaluate the type of pain complained of and the efficacy of analgesic treatments received by patients. We selected a limited time interval to evaluate development of pain; this decision had the specific aim of identifying clinical features that can guide attention from all the specialists involved in the patient's care and prevent misinterpretation of early clinical signs and symptoms.

\section{Materials and methods}

We undertook a retrospective, population-based study of the prevalence of CPSP in Rimini district, Italy. The study was approved by the local institutional review board and was conducted in accordance with the Declaration of Helsinki. We collected data from all patients who had had an ischemic stroke and were hospitalized in Rimini district (Rimini, Riccione, Cattolica, Santarcangelo, and Novafeltria hospitals) for the acute event in the period between 2008 and 2010. Stroke patients were identified by careful review of discharge diagnoses and imaging data (confirming the ischemic lesion in the CNS) obtained during hospitalization by a dedicated health care professional.

Rimini district has a population of 329,970. Stroke was diagnosed according to the World Health Organization 
(WHO) International Classification of Diseases 10th revision criteria (ICD-10). We used data only from patients who were admitted in our health district, which is characterized by a very homogeneous population, by a well structured model of assessment, diagnosis, and therapy, and has the possibility to count on a multidisciplinary task force of physicians specialized in the management of stroke.

\section{Data collection}

Analysis of medical charts enabled us to collect: demographic data; date of the stroke episode; clinical presentation of the stroke episode (describing the presence of neurologic comorbidities or other disorders; and motor and sensory deficits, ie, palsy, hemiparesis, aphasia, and dysarthria). We excluded patients with a past medical history of any persistent pain syndrome from the interview. Data on the prevalence of CPSP were collected by telephone interview performed at least 12 months after the stroke episode (range 12-36 months).

All patients reporting a pain state at the time of the telephone call were then interviewed in more depth, taking into account the following items using an ad hoc questionnaire:

- date of CPSP onset (at or after the time of stroke onset)

- pain intensity, using an 11-point visual analog scale (VAS) defining pain as mild (1-3), moderate (4-6), or severe $(>7)$

- pain distribution and characteristics (offering predefined descriptors to be chosen by the patient from a list)

- features of any neurologic sensory disturbances described by the patient (such as allodynia/paresthesia, dysesthesia)

- disability and impact of pain on physiologic functions, such as quality of sleep (sleep-wake mechanism) and self or assisted feeding

- treatment prescribed and efficacy/safety outcomes

- number and type of medications (nonsteroidal antiinflammatory drugs and/or acetaminophen, opioids, anticonvulsants, others) prescribed for pain control

- adverse events due to analgesic drugs (such as nausea, vomiting, dizziness, sedation)

- quality of life, using the Short Form-12 (SF-12) questionnaire. ${ }^{18}$

Patients with cognitive impairment were excluded, as were those with aphasia/dyslexia, even if low grade, those undergoing treatment with sedatives or major antipsychotic drugs, and those with epilepsy.

All patients whose answers suggested possible CPSP were asked to come to a consultation with a pain specialist.
The diagnosis of CPSP was supported by clinical history, imaging data confirming an ischemic lesion in the CNS, pain onset and characteristics, pain located in an area of the body corresponding to the lesion in the CNS, and a clinical and neurologic investigation (bedside sensory examination).

\section{Statistical analysis}

Continuous data were reported as the mean and \pm standard deviation and analyzed using the analysis of covariance model. Statistical significance was defined as $P<0.05$. Proportions were expressed as percentages.

\section{Results}

Throughout 24 months (2008-2010) we identified 1,494 patients who had had an ischemic stroke in the Rimini district, 322 of whom were deceased by the time of the telephone interview, 36 did not give their consent to participate in the study, and 535 were not contactable by telephone (Figure 1). We were able to contact 601 subjects, comprising $327(54.4 \%)$ males and $274(45.6 \%)$ females. The average age of those interviewed was $76.1 \pm 10.2$ (range 44-96) years. Sixty-six (11\%) patients suffered from CPSP, and

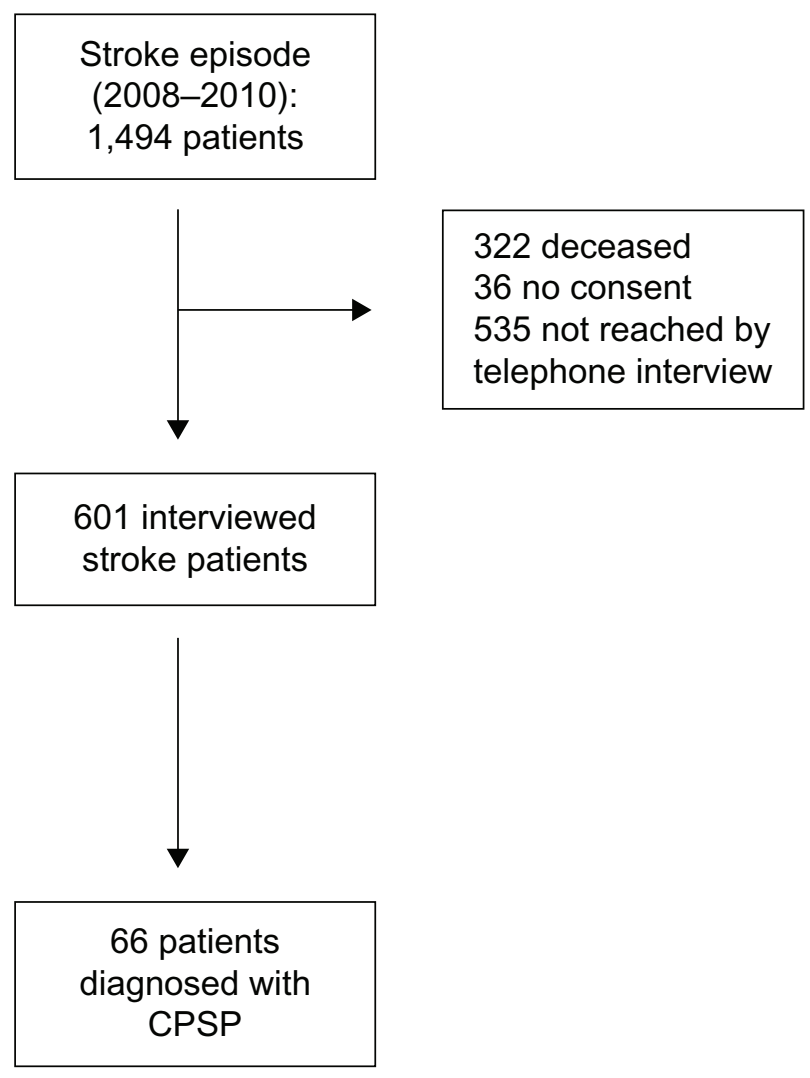

Figure I Study flowchart. Abbreviation: CPSP, central post-stroke pain. 
Table I Characteristics of patients referring central poststroke pain

\begin{tabular}{ll}
\hline Patients referring CPSP/interviewed pts (\%) & $66 / 60 \mathrm{I}$ (II) \\
Male (\%) & $38 / 327$ (II.6) \\
Female (\%) & $28 / 274$ (I0.2) \\
Average age (years) & $76.1 \pm 10.2$ \\
Age range (years) & $44-96$ \\
Average VAS score & $5.8 \pm 2.5$ \\
\hline
\end{tabular}

Abbreviations: CPSP, central post-stroke pain; VAS, visual analog scale; pts, patients.

comprised 38 males (11.6\% of total males) and 28 females (10.2\% of total females, Table 1$)$. On stratification of patients complaining of pain according to age, four patients (6\%) were aged $40-59$ years, $32(48.5 \%)$ were aged $60-79$ years, $27(40.9 \%)$ were aged $80-89$ years, and three (4.5\%) were aged $>90$ years. The majority of the patients reported moderate pain $(43.9 \%$ ), whereas $30.3 \%$ reported severe pain and $16.7 \%$ reported mild pain (Table 2 ). When asked about the timing of pain onset, $57.6 \%$ reported that their pain had started immediately after the stroke event, $19.7 \%$ after a month, and $19.7 \%$ after several months (Table 2). Pain was continuous in $59.6 \%$ of patients and intermittent in $36.5 \%$ (Table 2). Features of pain as reported by patients are listed in Table 3, which shows that pain perceived as a "needle puncture" was the main feature, described by $40.4 \%$ of patients, with $40.4 \%$ reporting thermal hyperesthesia and $38.5 \%$ reporting tactile hyperesthesia.

Table 2 CPSP characteristics

\begin{tabular}{lll}
\hline & $\mathbf{n}$ & $\%$ \\
\hline Pain intensity (VAS scale) & $1 \mathrm{l}$ & \\
Mild (I-3) & 29 & 16.7 \\
Moderate (4-7) & 20 & 43.9 \\
Severe (8-10) & 6 & 30.3 \\
Not defined by patient & & 9.1 \\
Pain location & 5 & \\
All limbs & 12 & 7.6 \\
Inferior limbs & 6 & 18.2 \\
Superior limbs & 13 & 9.1 \\
Half-body & 13 & 19.7 \\
Hand & 3 & 19.7 \\
Shoulder & 6 & 4.5 \\
Other & 8 & 9.1 \\
Not defined by patient & & 12.1 \\
Pain onset & 38 & \\
Immediately & 13 & 57.6 \\
After a month & 13 & 19.7 \\
After several months & 2 & 19.7 \\
Not defined by patient & & 3 \\
Pain temporal pattern & 39 & 59.2 \\
Continuous & 24 & 36.3 \\
Intermittent & 3 & 4.5 \\
Not defined by patient & Abbreviations: CPSP, central post-stroke pain; VAS, visual analog scale. \\
\hline
\end{tabular}

Abbreviations: CPSP, central post-stroke pain; VAS, visual analog scale.
Table 3 Pain descriptors and sensory disturbance reported by patients

\begin{tabular}{|c|c|c|c|c|c|c|}
\hline \multirow[t]{2}{*}{ Pain features } & \multicolumn{2}{|c|}{ Yes } & \multicolumn{2}{|c|}{ No } & \multicolumn{2}{|c|}{$\begin{array}{l}\text { Not } \\
\text { defined }\end{array}$} \\
\hline & $\mathbf{n}$ & $\%$ & $\mathbf{n}$ & $\%$ & n & $\%$ \\
\hline $\begin{array}{l}\text { Tactile } \\
\text { hyperesthesia }\end{array}$ & 20 & 38.5 & 30 & 57.7 & 2 & 3.8 \\
\hline $\begin{array}{l}\text { Thermal } \\
\text { hyperesthesia }\end{array}$ & 21 & 40.4 & 28 & 53.8 & 3 & 5.8 \\
\hline Tingling & 18 & 34.6 & 31 & 59.6 & 3 & 5.8 \\
\hline $\begin{array}{l}\text { Needle } \\
\text { puncture }\end{array}$ & 21 & 40.4 & 26 & 50.0 & 5 & 9.6 \\
\hline Swelling & 16 & 30.8 & 33 & 63.5 & 3 & 5.8 \\
\hline Duress & 11 & 21.2 & 36 & 69.2 & 5 & 9.6 \\
\hline
\end{tabular}

\section{Disability}

Almost one third (30.3\%) of those interviewed reported complete or partial motor palsy distributed in a part of the body ipsilateral to the stroke lesion, whereas $13.6 \%$ suffered from motor problems in the contralateral part of the body. Another group of patients (10.6\%) were affected by palsy in both lower limbs. Motor impairment persisted until the time of interview. It is interesting to note that $9.1 \%$ of these stroke patients did not report any motor impairment immediately after the onset of pathology.

With regard to walking ability, $15.2 \%$ of patients were still able to move without problems, but $39.4 \%$ were very impaired in their movements, with $43.9 \%$ being unable to walk at all. Only $6.1 \%$ recovered their working skills fully, $4.5 \%$ partially, and $83.3 \%$ did not recover these at all (Table 4).

\section{Pain interference with sleep, daily activities, social life, and quality of life}

Half $(50 \%)$ of the interviewed pain population could sleep in a restful way, $28.8 \%$ had some difficulty, and $21.8 \%$ could not sleep at all (Table 4). With regard to functional recovery,

Table 4 Disability and sleep disturbance

\begin{tabular}{|c|c|c|c|c|c|c|c|c|}
\hline & \multicolumn{2}{|c|}{ Good } & \multicolumn{2}{|c|}{ Partial } & \multicolumn{2}{|c|}{ None } & \multicolumn{2}{|c|}{$\begin{array}{l}\text { Not } \\
\text { definec }\end{array}$} \\
\hline & $\mathbf{n}$ & $\%$ & $\mathbf{n}$ & $\%$ & $\mathbf{n}$ & $\%$ & $\mathbf{n}$ & $\%$ \\
\hline Walking & 10 & 15.2 & 26 & 39.4 & 29 & 43.9 & I & 1.5 \\
\hline $\begin{array}{l}\text { Working skills } \\
\text { rehabilitation }\end{array}$ & 4 & 6.1 & 3 & 4.5 & 55 & 83.3 & 3 & 6.1 \\
\hline $\begin{array}{l}\text { Self care } \\
\text { rehabilitation }\end{array}$ & 22 & 33.3 & 9 & 13.6 & 33 & 50 & 2 & 3 \\
\hline $\begin{array}{l}\text { Social life } \\
\text { rehabilitation }\end{array}$ & 32 & 36.4 & 8 & 12.1 & 24 & 48.5 & 2 & 3 \\
\hline Sleeping & 33 & 50 & 19 & 28.8 & 14 & 21.8 & 0 & 0 \\
\hline
\end{tabular}


especially self-care and social life, we found that most of the stroke patients did not recover these abilities. One third $(33.3 \%)$ could take care of themselves as before the stroke event, $13.6 \%$ partially, and $50 \%$ not at all. With regard to social life, $36.4 \%$ reported good relationships as in the past, $12.1 \%$ partially recovered, and $48.5 \%$ had lost most of their social relationships, mainly as a result of their motor impairment and inability to leave home (Table 4). Quality of life was assessed using the SF-12 questionnaire, the results of which showed a mean physical component summary of $30.77 \pm 8.47$ and a mental component summary of $37.93 \pm 8.64$. These values were significantly $(P<0.05)$ lower than the average physical component summary of $51.2 \pm 7.4$ and mental component summary of $47.8 \pm 10.1$ reported by Gandek et al for the Italian population. ${ }^{24}$

\section{Pain treatments}

In total, $43.3 \%$ of patients with pain were prescribed analgesic/anti-inflammatory drugs, $10.1 \%$ pregabalin, $4.8 \%$ opioids, 5.5\% other drugs (including muscle relaxants and homeopathic or natural approaches), and 29.3\% were not prescribed any analgesic therapy (Table 5). Analgesics were prescribed immediately after the stroke episode in $36.7 \%$ of patients and some months later in $56.6 \%$ of cases, with $6.7 \%$ of patients receiving analgesics on an as-needed basis.

\section{Discussion}

CPSP has been underestimated for years, but nowadays is receiving wider interest. CPSP can develop immediately or up to 10 years after the stroke event, but usually develops 3-6 months after the stroke. ${ }^{11,25}$ Jönsson et al found that one third of patients complained of moderate to severe pain 4 months after stroke onset, and that $20 \%$ were still experiencing moderate to severe pain with increasing intensity one year later. ${ }^{14}$

Table 5 Pharmacological treatments prescribed

\begin{tabular}{lll}
\hline & $\mathbf{n}$ & $\%$ \\
\hline Medications & 29 & \\
Analgesic/anti-inflammatory & 18 & 43.3 \\
None & 7 & 29.3 \\
Pregabalin & 3 & 10.1 \\
Opioids & 4 & 4.8 \\
Other & 5 & 5.5 \\
Not defined & & 7 \\
Prescribed use of medications & 12 & \\
Continuous (daily assumption) & 18 & 60 \\
"As needed" therapy & & 60 \\
\hline
\end{tabular}

These findings suggest that a long follow-up period is necessary to evaluate CPSP, ${ }^{19}$ because pain may occur months or years after a stroke, and this may be due to the complex nature of post-stroke pain. Further, the clinical trial data underscore how difficult it is to treat this syndrome effectively.

The results of our study show a CPSP prevalence of $11 \%$, with no "gender" effect. This prevalence is within the range reported in the literature $(1 \%-12 \%) .{ }^{8,12,17}$ With regard to pain characteristics, consistent with the data in the literature, we found that tactile and thermal hyperesthesia were the most commonly described features, accompanied by sensations of "needle puncture", tingling, swelling, and pressure. In our sample, pain intensity was mainly moderate to severe and again, in accordance with the literature, was mainly continuous. However, in contrast with the published data, we found that the pain had started in the first month after the lesion in the majority of patients.

Location of the pain was variable, but hemisyndrome or lower limb involvement was frequent, resulting in motor impairment and disability affecting social relationships and causing sleep disturbance, in concordance with previous studies. ${ }^{8}$ The majority of patients were treated with analgesic/ anti-inflammatory drugs and anticonvulsants (pregabalin). This is in agreement with the study by Zorowitz et al, which reported that the most frequently prescribed pain medications for CPSP were analgesics, mainly acetaminophen and tramadol, followed by anticonvulsant. ${ }^{26}$ Use of pregabalin for treatment of central chronic pain ${ }^{27}$ and in particular of CPSP has been reported previously. ${ }^{28,29}$ Alarmingly, 29.3\% of our sample did not receive any analgesic treatment despite being in pain.

It is well established that quality of life is impaired in patients with mild to moderate deficits after brain infarction. ${ }^{30}$ Our results applying the SF-12 questionnaire, in accordance, showed scores lower than 50 in both the mental and physical domains and were statistically lower than for the average Italian population. ${ }^{24}$ This deterioration of patients' self-perceived physical and mental function is in agreement with previous studies. ${ }^{31,32}$

Our survey has the limitations common to all observational studies, including the limited geographic area covered. However, it can be seen as a pilot study for more detailed data collection, because further studies are necessary to address this issue. Despite the limitations of this study, we found a CPSP prevalence rate of $11 \%$, which is superimposable on the data reported in the literature and, interestingly, about $30 \%$ of these patients did not receive any treatment. 


\section{Conclusion}

Our study found that the prevalence of CPSP was as high as $11 \%$, with a consequent serious social and economic impact. In the majority of cases, pain appeared in the first month after the stroke, but there was a significant proportion of patients who developed pain several months after the event. Further, a high proportion of patients were not receiving treatment for their pain despite complaining of it, or were receiving an inappropriate treatment. Hence we believe that it is necessary to implement a campaign to educate physicians, including neurologists, who, in most cases, do not consider pain to be an important concern in stroke patients. Moreover, the issue of appropriate treatment of CPSP should be recognized as a challenge and addressed in further studies.

\section{Acknowledgment}

The study was supported by ISAL Foundation, Rimini, Italy; Dr CE Minella is supported by a research grant from Fondazione IRCCS Policlinico San Matteo.

\section{Disclosure}

The authors declare no conflicts of interest in this work.

\section{References}

1. Sarti C, Rastenyte D, Cepaitis Z, Tuomilehto J. International trends in mortality from stroke, 1968 to 1994. Stroke. 2000;31(7):1588-1601.

2. Bejot Y, Benatru I, Rouaud O, et al. Epidemiology of stroke in Europe: geographic and environmental differences. J Neurol Sci. 2007;262(1-2):85-88.

3. Rothwell PM, Coull AJ, Silver LE, et al. Population-based study of event-rate, incidence, case fatality, and mortality for all acute vascular events in all arterial territories (Oxford Vascular Study). Lancet. 2005;366(9499):1773-1783.

4. Sacco S, Stracci F, Cerone D, Ricci S, Carolei A. Epidemiology of stroke in Italy. Int J Stroke. 2011;6(3):219-227.

5. Kumar G, Soni CR. Central post-stroke pain: current evidence. J Neurol Sci. 2009;284(1-2):10-17.

6. Misra UK, Kalita J, Kumar B. A study of clinical, MRI and somatosensory evoked potential in central post stroke pain. J Pain. 2008;9:1116-1122.

7. Treede RD, Jensen TS, Campbell JN, et al. Neuropathic pain: redefinition and a grading system for clinical and research purposes. Neurology. 2008;70(18):1630-1635.

8. Klit H, Finnerup NB, Jensen TS. Central post-stroke pain: clinical characteristics, pathophysiology, and management. Lancet Neurol. 2009;8(9):857-868.

9. Merskey HM, Bogduk N. Classification of Chronic Pain. 2nd ed. Seattle, WA: IASP Press; 1994.

10. Bowsher D. Stroke and central poststroke pain in an elderly population. J Pain. 2001;2(5):258-261.

11. Nasreddine ZS, Saver JL. Pain after thalamic stroke: right diencephalic predominance and clinical features in 180 patients. Neurology. 1997;48(5):1196-1199.

12. Kong KH, Woon VC, Yang SY. Prevalence of chronic pain and its impact on health-related quality of life in stroke survivors. Arch Phys Med Rehabil. 2004;85(1):35-40.
13. Klit H, Finnerup NB, Overvad K, Andersen G, Jensen TS. Pain following stroke: a population-based follow-up study. PLoS One. 2011;6(11):e27607.

14. Jönsson AC, Lindgren I, Hallström B, Norrving B, Lindgren A. Prevalence and intensity of pain after stroke: a population based study focusing on patients' perspectives. J Neurol Neurosurg Psychiatry. 2006;77(5):590-595.

15. Andersen G, Vestergaard K, Ingeman-Nielsen M, Jensen TS. Incidence of central post-stroke pain. Pain. 1995;61:187-194.

16. Weimar C, Kloke M, Schlott M, Katsarava Z, Diener HC. Central poststroke pain in a consecutive cohort of stroke patients. Cerebrovasc Dis. 2002;14(3-4):261-263.

17. Widar M, Ahlstrom G. Disability after a stroke and the influence of longterm pain on everyday life. Scand J Caring Sci. 2002;16(3):302-310.

18. Hansen AP, Marcussen NS, Klit H, Andersen G, Finnerup NB, Jensen TS. Pain following stroke: a prospective study. Eur J Pain. 2012;16(8):1128-1136.

19. Hansson P. Post-stroke pain case study: clinical characteristics, therapeutic options and long-term follow-up. Eur J Neurol. 2004;11 Suppl 1:22-30.

20. Jonkman EJ, de Weerd AW, Vrijens NL. Quality of life after a first ischemic stroke. Long-term developments and correlations with changes in neurological deficit, mood and cognitive impairment. Acta Neurol Scand. 1998;98(3):169-175.

21. Choi-Kwon S, Choi JM, Kwon SU, Kang DW, Kim JS. Factors that affect the quality of life at 3 years post-stroke. J Clin Neurol. 2006;2(1):34-41.

22. Brainin M, Norrving B, Sunnerhagen KS, et al. International PSS Disability Study Group. Poststroke chronic disease management: towards improved identification and interventions for poststroke spasticityrelated complications. Int J Stroke. 2011;6(1):42-46.

23. Kumar S, Selim MH, Caplan LR. Medical complications after stroke. Lancet Neurol. 2010;9(1):105-118.

24. Gandek B, Ware JE, Aaronson NK, et al. Cross-validation of item selection and scoring for the SF-12 Health Survey in nine countries: results from the IQOLA Project. International Quality of Life Assessment. J Clin Epidemiol. 1998;51(11):1171-1178.

25. Canavero S, Bonicalzi V. Central pain of brain origin: epidemiology and clinical features. In: Central Pain Syndrome: Pathophysiology, Diagnosis and Management. 1st ed. Cambridge: Cambridge University Press; 2007.

26. Zorowitz RD, Smout RJ, Gassaway JA, Horn SD. Usage of pain medications during stroke rehabilitation: the Post-Stroke Rehabilitation Outcomes Project (PSROP). Top Stroke Rehabil. 2005;12(4):37-49.

27. Vranken JH, Dijkgraaf MG, Kruis MR, van der Vegt MH, Hollmann MW, Heesen M. Pregabalin in patients with central neuropathic pain: a randomized, double-blind, placebo-controlled trial of a flexible-dose regimen. Pain. 2008;136(1-2):150-157.

28. Kim JS. Post-stroke pain. Expert Rev Neurother. 2009;9(5):711-721.

29. Kim JC, Choi YS, Kim KN, Shim JK, Lee JY, Kwak YL. Effective dose of peri-operative oral pregabalin as an adjunct to multimodal analgesic regimen in lumbar spinal fusion surgery. Spine. 2011;36(6):428-433.

30. Jaracz K, Kozubski W. Quality of life in stroke patients. Acta Neurol Scand. 2003;107(5):324-329.

31. Wolfe CD, Crichton SL, Heuschmann PU, et al. Estimates of outcomes up to ten years after stroke: analysis from the prospective South London Stroke Register. PLoS Med. 2011;8(5):e1001033.

32. Jönsson AC, Lindgren I, Hallström B, Norrving B, Lindgren A. Determinants of quality of life in stroke survivors and their informal caregivers. Stroke. 2005;36(4):803-808. 
Journal of Pain Research

\section{Publish your work in this journal}

The Journal of Pain Research is an international, peer-reviewed, open access, online journal that welcomes laboratory and clinical findings in the fields of pain research and the prevention and managemen of pain. Original research, reviews, symposium reports, hypothesis formation and commentaries are all considered for publication.
Dovepress

The manuscript management system is completely online and includes a very quick and fair peer-review system, which is all easy to use. Visit http://www.dovepress.com/testimonials.php to read real quotes from published authors.

\footnotetext{
Submit your manuscript here: http://www.dovepress.com/journal-of-pain-research-journal
} 